\title{
CONSUMIDOR: (IN)EFICIÊNCIA NA CONCRETIZAÇÃO DE DIREITOS
}

\section{Franco Scortegagna ${ }^{1}$ Hellen Sudbrack ${ }^{2}$}

Resumo: A investigação-objeto da presente pesquisa busca analisar a concretização dos direitos do consumidor sob o prisma da (in)eficiência da proteção dos mesmos, os quais se veem vulneráveis quando não podem contar com órgãos de defesa nos respectivos municípios. A propósito, cabe dizer que mesmo diante do avanço significativo trazido pelo Código de Defesa do Consumidor, ainda ocorrem resistências e diversos tipos de afrontas à lei consumerista, devido à falta de informação por parte dos consumidores no que tange a verdade sobre seus direitos, fato que representa um problema ideológico e político.

Palavras-chave: Consumidor. Direitos. Dignidade Humana. Proteção; Vulnerabilidade.

\section{CONSUMER: (IN) EFFICIENCY IN REALIZING RIGHTS}

\begin{abstract}
The object-investigation of this research seeks to analyze the realization of consumer rights under the prism of the (in)efficiency of their protection, who see themselves vulnerable when they cannot count on defense agencies in their respective municipalities. By the way, it should be said that even in the face of the significant advance brought by the Consumer Protection Code, resistance and various types of affronts to the consumer law still occur, due to the lack of information on the part of consumers regarding the truth about their rights, a fact which represents an ideological and political problem.
\end{abstract}

Keywords: Consumer. Rights. Human dignity. Protection; Vulnerability.

\section{Introdução}

A presente pesquisa objetiva analisar os parâmetros em torno da concretização dos direitos do consumidor sob o prisma da (in)eficiência da proteção dos mesmos, os quais se veem vulneráveis quando não podem contar com órgãos de defesa em seus municípios.

A importância da abordagem consiste na observação de que as relações de consumo na sociedade atual sofrem constantes inovações, frequentemente mediante a inserção de novas tecnologias, decorrentes dos fenômenos da globalização, economia e política, que influenciam

\footnotetext{
${ }^{1}$ Mestre em Direito pela Universidade de Passo Fundo. Especialista em Direito do Consumidor pela UNIASSELVI. Especialista em Direito Processual pela Universidade de Passo Fundo. Professor da Faculdade de Direito da Universidade de Passo Fundo. Orientador do Balcão do Consumidor de Passo Fundo. E-mail: fscortegagna@upf.br.

${ }^{2}$ Advogada. Mestra em Direito pela Universidade de Passo Fundo. Bacharela em Ciências Jurídicas e Sociais pela Universidade de Passo Fundo. E-mail: he.sudbrack@gmail.com.
} 
direta ou indiretamente na efetivação de ações para a proteção e defesa do consumidor.

Interpreta-se que existem muitos meios através dos quais que a proteção e defesa do consumidor se efetivem de forma ampla e irrestrita no território nacional. Este cenário reflete num déficit de órgãos de defesa do consumidor. Desse modo, o assunto será abordado dando destaque, na primeira parte deste artigo, aos direitos e desafios do consumidor com base em Habermas. Em um segundo momento, serão estudados os aspectos concernentes a vulnerabilidade do consumidor.

O estudo observará a lógica operacional do método hipotético-dedutivo, mediante abordagem qualitativa e pesquisa bibliográfica.

\section{Direito e desafios em Habermas}

Observa-se ainda por parte de segmentos econômicos, que buscam o mero interesse do lucro fácil de regras fundadas nos séculos XVIII e XIX, certa resistência na adoção de princípios éticos e à dignidade da pessoa humana em suas relações negociais, desse modo reagem contumaz contra o Código de Defesa do Consumidor ${ }^{3}$.

Esquecendo que ele visa assegurar a livre concorrência, pois, ao impor indiscriminadamente, de forma cogente, a obediência às mesmas regras sobre dever de informação, qualidade, segurança e oferta, impede a concorrência desleal e o aumento fácil dos lucros (HABERMAS, 2003, p. 25/26).

$\mathrm{O}$ assunto relacionado a defesa do consumidor tornou-se tão importante para o cidadão brasileiro, que foi elevado ao patamar de direito fundamental da pessoa, conforme artigo $5^{\circ}$, inciso XXII, da Constituição Federal de 1988 e de princípio constitucional da ordem

\footnotetext{
${ }^{3}$ A propósito, cabe mencionar as reflexões de Habermas: "O princípio da teoria do discurso, configurado inicialmente de acordo com a formação da vontade individual, comprovou-se no campo ético e no da filosofia moral. [...] questões da teoria do direito rompem a limine o quadro de um reflexo meramente normativa. Apoiada no princípio do discurso, a teoria do direito - e do Estado de Direito - precisa sair dos trilhos convencionais da filosofia política e do direito, mesmo que continue assimilando seus questionamentos. Na teoria do direito, sociólogos, juristas e filósofos discutem sobre a determinação apropriada da relação entre facticidade e validade, chegando a premissas e estratégias de pesquisas diferentes. O conceito do agir comunicativo atribui às forças ilocucionárias da linguagem orientada ao entendimento a função importante da coordenação da ação. A tensão entre facticidade e validade, que se introduz no próprio modo de coordenação da ação, coloca exigências elevada para a manutenção de ordens sociais. Transportando os conceitos fundamentais da "razão prática" para os da "racionalidade comunicativa", não há necessidade de lançar fora os questionamentos e as soluções desenvolvidas na filosofia prática, desde Aristóteles até Hegel, o que constitui uma grande vantagem para a teoria da sociedade. Todavia, o conceito sucessor "razão comunicativa" conserva fragmentos idealista desta herança, os quais nem sempre são vantajosos, no contexto modificado de uma teoria comprometida com o esclarecimento" (HABERMAS, 2003, p. 23/24)
} 
econômica, expresso no artigo 170, inciso V, da Constituição Federal de 1988. (SILVA, 2004, p. 7).

$\mathrm{Na}$ concepção de Habermas o direito se interliga não apenas com o poder administrativo e o dinheiro, como também com a solidariedade, ele absorve, em suas realizações integradoras, imperativos de diferentes procedências. A tensão entre o idealismo do poder direito constitucional e o materialismo de uma ordem jurídica, especialmente de um direito econômico, que simplesmente reflete a distribuição desigual do poder social, encontra o seu eco no desencontro entre as abordagens filosóficas e empíricas do direito (HABERMAS, 2003, p. 63).

Pode-se inferir que a complexidade da administração pública dificulta a participação social, são ideológicas e encontram-se em argumentos endógenos e exógenos à gestão da coisa pública (LEAL, 2006, p. 70-72).

A capacidade de mobilização e organização social oportunizou um processo de conscientização política gradual e em desenvolvimento dos novos movimentos sociais, que procuravam compreender os códigos fechados da linguagem do poder e da administração, a fim de buscar a implementação e promoção de suas prerrogativas garantidas pelo sistema jurídico vigente (LEAL, 2006, p. 71).

De acordo com Leal, à participação pública dos sujeitos sociais e a representação institucional se faz necessária, sendo possível imaginar a cooperação entre partidos políticos, Legislativo, Executivo e movimentos sociais organizados, pois se interpreta que todos buscam o mesmo objetivo, qual seja:

[...] o interesse público - sempre tensional e conflituoso. A instância formal de representação comunitária pode e deve instituir um espaço permanente de interlocução com a instância informal de apresentação desta mesma comunidade, e deles todos com o Estado Administrador (LEAL, 2006, p. 73).

A Administração Pública deve criar condições à instituição de uma comunicação e linguagem de fácil compreensão a todos, de maneira que suas questões normativas e operativas tornem-se validadas, com isso, deixam de ser suas e passam a ser da comunidade. Assim, de acordo com Habermas,

[...] o direito moderno se adequa especialmente à integração social de sociedades econômicas que, em domínios de ação neutralizados do ponto de vista ético, dependem das decisões descentralizadas de sujeitos singulares orientados pelo 
sucesso próprio. $\mathrm{O}$ direito não pode satisfazer apenas às exigências funcionais de uma sociedade complexa, devendo levar em conta também as condições precárias de uma integração social que se realiza, em última instância, através das realizações de entendimento de sujeitos que agem comunicativamente, isto é, através da aceitabilidade de pretensões de validade (2003, p. 114).

O processo de normatização do Direito se obtém através do processo legislativo. Contudo, o processo legislativo autonomamente não é fonte da legitimidade do direito, a ideia de que o ordenamento jurídico se constitui enquanto uma instância externa aos cidadãos, heterônoma, cede lugar à ideia de uma produção efetiva de seres livres que têm, no ordenamento jurídico, a manifestação de sua vontade livre. Portanto, o Direito é, ao mesmo tempo, criação e reflexo da produção da produção discursiva da opinião e da vontade dos membros de uma dada comunidade jurídica. Por este princípio do discurso, neutro do ponto de vista normativo, Habermas fundamenta o Direito de modo a estabilizar a tensão entre autonomia privada e pública por meio do procedimento legislativo (MOREIRA, 1999, p. 157/158)

Assim a co-originalidade da autonomia privada e pública se revela apenas quando se decifra "o modelo da autolegislação através da teoria do discurso, que ensina serem os destinatários simultaneamente os autores de seus direitos" (MOREIRA, 1999, p. 157/158). O processo legislativo isolado não é fonte de legitimidade da lei. Enquanto instância externa aos cidadãos tal processo não se legitima, devendo para tanto partir da própria população a criação das leis, sendo esta mesma população efetivamente o início e o fim do processo legislativo, tal feito dar-se-ia através da ação comunicativa.

A razão comunicativa adquire força normativa apenas após um consenso discursivamente estabelecido, melhor dizendo, após a discussão, a análise de determinado assunto pela coletividade e sua aprovação pela maioria (MOREIRA, 1999, p. 157/158). Interessante citar a posição de Habermas sobre a opinião pública, onde o autor afirma que "valendo-se do procedimento da discussão parlamentar, a opinião pública faz chegar ao governo seus desejos e, por sua vez, o governo põe a opinião pública em conhecimento de sua política” (HABERMAS, 2002, p. 263). Deste modo a opinião pública domina, entretanto não governa.

A razão comunicativa deve afastar-se de princípios com contornos morais, assumindo uma posição deontologicamente neutra (MOREIRA, 1999, p. 157-158). Quanto mais o direito, enquanto instituição, expressar a vontade discursiva dos cidadãos mais legítimo será. 
Nesse sentido, destaca-se o inciso VII, artigo $6^{\circ}, \mathrm{CDC}^{5}$, que assegura e garante aos consumidores o acesso aos órgãos judiciários e administrativos com vistas à prevenção ou reparação de danos patrimoniais e morais, individuais, coletivos ou difusos, garantida a proteção Jurídica, administrativa e técnica aos necessitados. O inciso mencionado trata-se de uma indispensabilidade ao código, já que de nada adianta garantir direitos de defesa ao consumidor, sem garantir que exista a realização dos mesmos. É o direito à execução, à

\footnotetext{
${ }^{4}$ Art. $6^{\circ}$ São direitos básicos do consumidor:

I - a proteção da vida, saúde e segurança contra os riscos provocados por práticas no fornecimento de produtos e serviços considerados perigosos ou nocivos;
}

II - a educação e divulgação sobre o consumo adequado dos produtos e serviços, asseguradas a liberdade de escolha e a igualdade nas contratações;

III - a informação adequada e clara sobre os diferentes produtos e serviços, com especificação correta de quantidade, características, composição, qualidade, tributos incidentes e preço, bem como sobre os riscos que apresentem;

IV - a proteção contra a publicidade enganosa e abusiva, métodos comerciais coercitivos ou desleais, bem como contra práticas e cláusulas abusivas ou impostas no fornecimento de produtos e serviços;

V - a modificação das cláusulas contratuais que estabeleçam prestações desproporcionais ou sua revisão em razão de fatos supervenientes que as tornem excessivamente onerosas;

VI - a efetiva prevenção e reparação de danos patrimoniais e morais, individuais, coletivos e difusos;

VII - o acesso aos órgãos judiciários e administrativos com vistas à prevenção ou reparação de danos patrimoniais e morais, individuais, coletivos ou difusos, assegurada a proteção Jurídica, administrativa e técnica aos necessitados;

VIII - a facilitação da defesa de seus direitos, inclusive com a inversão do ônus da prova, a seu favor, no processo civil, quando, a critério do juiz, for verossímil a alegação ou quando for ele hipossuficiente, segundo as regras ordinárias de experiências;

IX - (Vetado);

$\mathrm{X}$ - a adequada e eficaz prestação dos serviços públicos em geral.

Parágrafo único. A informação de que trata o inciso III do caput deste artigo deve ser acessível à pessoa com deficiência, observado o disposto em regulamento. BRASIL. Código de Defesa do Consumidor. Disponível em: <http://www.planalto.gov.br/ccivil_03/leis/l8078.htm> Acesso em: 6 set., 2019.

${ }^{5}$ Comentam Okazaki e Azevedo que: “[...] a relação jurídica de consumo, em sua essência era por si só desigual, não se amoldando, portanto, aos paradigmas de igualdade difundidos pelo Estado Democrático de Direito. Advindo daí a necessidade de uma tutela específica, de princípios e métodos que lhe outorgasse identidade, de novos paradigmas legais para recompor o equilíbrio formal e jurídico entre as partes integrantes da relação. Foi esta a proposta inserida em nossa Constituição. Diante disto, é que se encontra a afinidade entre as normas de proteção ao consumidor com a tópica, pois, tratando-se esta de uma técnica que se orienta para o problema, apontando diversas práticas com o objetivo de resolver conflitos e produzir decisões adequadas a sociedade e ao interesse coletivo, não resta dúvidas da sua influência para o alcance dos fins que se busca mediante a aplicação das normas do consumidor para a concretização do Estado Democrático de Direito. Se as normas de defesa do consumidor visam o equilíbrio entre este e o fornecedor, com o condão maior de dar proteção ao hipossuficiente da relação de consumo, a aplicação da técnica tópica se mostra por demais eficiente para atingir o objetivo de uma proposta tutelar efetiva. O conjunto de normas sem aptidão prática em pouco é valorada. Todavia, se interpretada em todas as circunstâncias sociais que se fazem essenciais sua utilização, em muito se torna benéfica, visto que proporciona a eficácia dos direitos e garantias assegurados a todos que de tais regras e tutelas necessitem. Desse modo, é que a técnica tópica em tudo se cataloga com as normas estabelecidas no Código de Defesa do Consumidor, pois, por ser um conjunto de regras abertas para que, tenha relação fática-jurídica em diversas situações ocorridas no âmbito consumerista, reflete a necessidade de utilizar-se desta, para que assim, sejam resolutos os conflitos existentes no âmbito social. O próprio conceito de consumidor, previsto no art. $2^{\circ}$, caput, da Lei 8.078/90, não pode ser assimilado sem o desenvolvimento do raciocínio tópico. Referida regra dispõe que "consumidor é toda pessoa física ou jurídica que adquire ou utiliza produto ou serviço como destinatário final". No entanto, o sentido da expressão destinatário final somente pode ser alcançado mediante o raciocínio tópico" (OKAZAKI; AZEVEDO, 2014. p. 445). 
concretização de sua defesa como consumidor. É possível afirmar que, apesar da evolução na tutela do consumidor, de uma legislação minuciosa, reconhecida como um dos melhores sistemas de proteção ao consumidor no mundo, ainda existe um caminho a ser trilhado no combate às práticas de fornecedores que insistem em contar com a ignorância e a falta de tempo dos consumidores na busca pelos seus direitos. $\mathrm{O}$ ideal da dignidade da pessoa humana, um dos fundamentos do Estado Democrático de Direito, vai além de um tratamento digno no âmbito da saúde, moradia, e o respeito à integridade física do cidadão. ${ }^{6}$

A dignidade está inserida no âmago do exercício da cidadania, proporcionou que se usufrua de um status ativo nos direitos fundamentais, participando da construção de uma sociedade mais justa. Por óbvio que uma sociedade sem conflitos é uma "utopia", todavia, o respeito aos direitos do consumidor é um grande passo para reduzir as demandas levadas à apreciação do Poder Judiciário, bem como uma oportunidade de amadurecimento da cidadania (NETO; COSTA, 2015, p. 236).

\section{A vulnerabilidade como característica consumerista a ser predominantemente observada}

A vulnerabilidade do consumidor diz respeito ao reconhecimento da parte mais fraca da relação de consumo, tendo em vista que o fornecedor é quem detém mais poder. Com isto, considerando o desequilíbrio que ocorria nas relações de consumo mais remotas, se justificou a necessidade do reconhecimento da vulnerabilidade do consumidor.

Procedente citar também que a expressão Hipervulnerabilidade fora criada pelo Ministro do Superior Tribunal de Justiça (STJ), um dos autores do Código de Defesa do Consumidor, Antônio Herman V. Benjamin. Cabe inferir que, o CDC adotou um regime jurídico que visa promover a igualdade do mais fraco, tendo em vista que este possui uma vulnerabilidade em relação ao outro polo da relação. Sendo que a vulnerabilidade de que falamos aqui é característica primordial do direito do consumidor.

De acordo com Moraes (2009, p. 125):

\footnotetext{
6 “A ideia dos direitos humanos e a da soberania do povo determinam até hoje a autocompreensão normativa de Estados de direito democráticos. [...] a história da teoria é um componente necessário, um reflexo da tensão entre facticidade e validade, entre a positividade do direito e a legitimidade pretendida por ele, latentes no próprio direito. Essa tensão não pode ser trivializada nem ignorada, porque a racionalização do mundo da vida impede cada vez mais que se cubra a necessidade de legitimação do direito estabelecido - apoiado nas decisões modificáveis de um legislador político - lançando mão da tradição e da eticidade consuetudinária. Convém lembrar o potencial de racionalidade liberado pela cultura e pela socialização, que fortaleceram o direito a partir das primeiras codificações ocorridas no final do século XIX”. (HABERMAS, 2003. p. 127/128).
} 
[...] vulnerabilidade, sob o enfoque jurídico, é então, o princípio pelo qual o sistema jurídico positivado brasileiro reconhece a qualidade ou condição daquele(s) sujeito(s) mais fraco(s) na relação de consumo, tendo em vista a possibilidade de que venha(m) a ser ofendido(s) ou ferido(s), na sua incolumidade física ou psíquica, bem como no âmbito econômico, por parte do(s) sujeito(s) mais potente(s) da mesma relação.

Portanto, o princípio da vulnerabilidade é o princípio básico, o qual justifica a existência, bem como a aplicação do Direito do Consumidor, decorrendo diretamente do princípio da igualdade, pois tal condição, no que diz respeito a consumidores, pessoas físicas, é presunção legal e absoluta. Schmitt faz importante reflexão acerca do momento em que se passou a perceber que de fato o consumidor é um ser vulnerável, uma vez que abusos vinham ocorrendo no mercado, o que acabou por evidenciar esta fragilidade, conforme segue:

A compreensão de que o consumidor é um agente vulnerável passa a ser
desenvolvida no início do século XX, considerando-se os abusos do mercado que
demonstravam a fragilidade desse sujeito, o que resta bastante evidenciado, por
exemplo, diante da instrumentalização característica dos negócios massificado,
configurados em contratos de adesão, ou em condições gerais, figuras pré-redigidas
pelos fornecedores, que, não raro, colocam os consumidores em posição de
desequilíbrio negocial, motivo pelo qual vieram a ser reguladas por leis, como é o
caso, por exemplo, do art. 54 do CDC, que exige pautas mínimas de conformação
desses instrumento contratuais com a perspectiva de proteção do consumidor
(SCHMITT, 2014, p. 206).

A vulnerabilidade é um dos indicadores de que é necessária a proteção dos consumidores, o que se faz, principalmente, através de intervenções estatais, com o auxílio dos atores da política nacional de relações de consumo. A propósito Marques ressalta que:

Uma das partes é vulnerável (art. $4^{\circ}$, I), é o polo mais fraco da relação contratual, pois não pode discutir o conteúdo do contrato: mesmo que saiba que determinada cláusula é abusiva, só tem uma opção, "pegar ou largar", isto é, aceitar o contrato nas condições que lhe oferece o fornecedor ou não aceitar e procurar outro fornecedor. Sua situação é estruturalmente e faticamente diferente da do profissional que oferece o contrato. Este desequilíbrio de força entre os contratantes é a justificação para um tratamento desequilibrado e desigual dos cocontratantes, protegendo o direito aquele que está na posição mais fraca, o vulnerável, o que é desigual fática e juridicamente (2014, p. 320).

Então, o motivo do reconhecimento da vulnerabilidade do consumidor, por diferentes fatores, o que justifica as normas de proteção consumeristas. Esta característica atribuída aos consumidores fez com que a doutrina e a jurisprudência dividissem-na em técnica, jurídica, 
informacional, social, ambiental e psíquica. E, em relação à vulnerabilidade técnica, Cavalieri Filho explica que:

A vulnerabilidade técnica decorre do fato de não possuir o consumidor conhecimentos específicos sobre o processo produtivo, bem assim dos atributos específicos de determinados produtos ou serviços pela falta ou inexatidão das informações que lhe são prestadas. É o fornecedor quem detém o monopólio do conhecimento e do controle sobre os mecanismos utilizados na cadeia produtiva. Ao consumidor resta, somente, a confiança, a boa-fé, no proceder honeste, leal do fornecedor, fato que lhe deixa sensivelmente exposto (2010, p. 45).

Verifica-se, que esta vulnerabilidade diz respeito, exclusivamente, à características, como o próprio nome já diz, técnicas dos produtos e serviços. No que se refere à jurídica, decorre, por exemplo, das dificuldades que os consumidores encontram para fazer valer seus direitos, seja administrativa ou judicialmente. Logo, é uma falta de conhecimentos jurídicos específicos, sendo no CDC presumida para o consumidor não profissional e para a pessoa física, uma vez que não são obrigados a deterem tais especificidades, diferentemente do que ocorre com consumidores, pessoas jurídicas, que já possuem parcela de conhecimento jurídico.

Com relação à vulnerabilidade informacional, está ligada intimamente com a era da informação, onde o poder está detido nesta, o que acaba gerando ao consumidor fraqueza em face dos fornecedores, posto que estes possuem maiores informações sobre seus produtos e serviços em relação aos usuários e fornecedores, e acerca disto Schmitt informa que:

\footnotetext{
Um intenso fator de desequilíbrio, nesse caso, atinge o consumidor, que tem o minus da informação, o que impõe ao fornecedor, o expert da cadeia de consumo, a adoção de aparatos que compensem esse novo fator de risco para a sociedade, em especial, aos consumidores. Assim, é dever do fornecedor compartilhar aquilo que somente ele sabe acerca do produto ou serviço, desde os primórdios de um processo de elaboração de bens, até a definição de elementos negociais inseridos nos contratos entabulados com os consumidores. (2014, p. 206).
}

Existe ainda a vulnerabilidade social, sobre esta pode-se mencionar que decorre primordialmente da disparidade de forças existente entre consumidores, fornecedores e agentes econômicos, demonstrando que estes possuem maiores condições e forças de impor suas vontades (MORAES, 2009, p. 179).

Outra característica que se evidencia da vulnerabilidade social, que doutrinariamente é chamada também de econômica, como destaca Moraes, é quando os consumidores 
apresentam dificuldade de locomoção para grandes centros, precisando se contentar com produtos que se encontram acessíveis, porém sem preços atrativos ou ainda boa qualidade, devido a falta de concorrência (2009, p. 179).

A vulnerabilidade ambiental está ligada, especificamente, com os riscos causados não só ao meio ambiente, mas também à eventuais danos que possam ocasionar aos usuários e consumidores de produtos e serviços. A noção de vulnerabilidade psíquica, pode ser interpretada coo àquela que torna o consumidor parte mais fraca da relação devido às técnicas publicitárias empenhadas pelos fornecedores para atingirem efeitos sob as escolhas dos consumidores, fazendo com que estes "mentalmente" priorizem o produto da marca " $\mathrm{x}$ " em detrimento do da marca "y", por exemplo. Comentadas algumas definições de vulnerabilidade, pode-se destacar o reconhecimento deste no campo do direito do consumidor, visto que busca estabelecer a igualdade entre os sujeitos. Salienta Bonatto que:

[...] o princípio da vulnerabilidade representa a defesa dos princípios constitucionais da função social da propriedade, da defesa do consumidor, da redução das desigualdades regionais e sociais e da busca do pleno emprego somente surgem caso existam consumidores para investir nas empresas, as quais repassarão estas riquezas novamente para seus consumidores, que são seus empregados (2009, p. 47).

Destaca-se como fundamental o papel da vulnerabilidade no campo consumerista, principalmente no que diz respeito ao consumismo, salienta-se a seguir os órgãos competentes que atuam na defesa dos interesses consumeristas.

Ao se afrontar os consumidores com sua vulnerabilidade perante grandes empresas e corporações, que, além de capital financeiro, detém informações muito mais privilegiadas, é frequente essa ocorrência, na medida em que

[...] na última década, milhões de brasileiros ingressaram no mercado de consumo e passaram a relacionar-se com grandes fornecedores, que tem como marca a impessoalidade no atendimento e a virtualização dos serviços. A falta de preparo desses consumidores e a aplicação de práticas abusivas por meio de pequenas lesões repetitivas aumentam os lucros e as demandas que chegam ao Poder Judiciário e aos órgãos de defesa do consumidor, que não estão presentes na maioria dos municípios, ou não têm estrutura adequada para prestar um bom atendimento ao cidadão (SILVA, 2015, p. 278).

Cumpre analisar que o cenário pandêmico atualmente vivenciado e o consequente aumento da frequência de compras realizadas por meio virtual exige um olhar ainda mais atento das autoridades para com a proteção desses direitos aos consumidores, já que o 
isolamento social em função da pandemia da Covid-19 tem contribuido para essa prática, que se intensificou ainda mais no último ano.

O Código de Defesa do Consumidor instituiu a política nacional das relações de consumo visando disponibilizar ao consumidor instrumentos capazes de colocá-lo em condições de igualdade perante o fornecedor. A intenção foi fazer com que a defesa do consumidor passasse a constituir-se em um meio de compatibilizar e harmonizar os interesses entre os sujeitos da relação de consumo.

Então, objetivo da política nacional das relações do consumo é, basicamente, a promoção dos interesses do consumidor, tendo em vista a vulnerabilidade deste em decorrência do poderio dos fornecedores, buscando com que exista um equilíbrio na relação de consumo.

Tal política estabelece um rol de objetivos e princípios a serem seguidos, de forma efetiva, pelos consumidores, fornecedores, assim como pelo Estado. Logo, para a efetivação da política nacional das relações de consumo, o legislador estabeleceu no art. $4^{\circ}$ do Código de Defesa do Consumidor seus principais objetivos, sendo eles: o atendimento às necessidades dos consumidores; o respeito à sua dignidade, saúde e segurança; a proteção de seus interesses econômicos; a melhoria da sua qualidade de vida e a transparência e harmonia nas relações de consumo. Pode-se dizer que a defesa do consumidor funda-se principalmente em uma diretriz que possui como alvo as boas relações de consumo, a qual apenas é atingida com a utilização de alguns instrumentos por parte do consumidor.

Com isto, deve-se ressaltar que tais instrumentos estão disciplinados no artigo $5^{\circ}$ do Código de Defesa do Consumidor, sendo eles: as Promotorias de Justiça de Defesa do Consumidor, no âmbito do Ministério Público; as delegacias de polícia especializadas no atendimento de consumidores vítimas de infração penas de consumo; e os Juizados Especiais de Pequenas Causas e Varas Especializadas para a solução de litígios de consumo. Todavia, o estabelecido no art. 5 do $\mathrm{CDC}$ trata-se de um rol exemplificativo e não taxativo, neste contexto, cabe citar a Secretaria Nacional do Consumidor - SENACON, os PROCONS e, também, da Associação de Defesa do Consumidor.

Ocorre que a presença do Estado nas relações de consumo está intimamente ligada com o princípio da vulnerabilidade do consumidor. Então, sempre que ocorrer esta vulnerabilidade, o Estado deve intervir para proteger o consumidor, que é a parte mais fraca da relação de consumo. No entanto, essa proteção deve ser efetivada tanto por meios 
legislativos, como judiciários ou administrativos, visando unicamente garantir o respeito às normas de defesa dos consumidores. Para Marques, o Estado detém uma força positiva no sentido de realizar determinadas tarefas, veja-se:

\begin{abstract}
Tendo em vista a evolução do direito, como um instrumento de mudança social, os direitos previstos no texto constitucional, tanto os direitos políticos (os chamados direitos fundamentais de $1^{\text {a }}$ geração), quanto os direitos econômicos e sociais (direitos fundamentais de $2^{\mathrm{a}}$ e $3^{\mathrm{a}}$ gerações), passam a ter também uma eficácia positiva. Se tradicionalmente estas previsões constitucionais possuíam um efeito meramente negativo, no sentido de proibir o Estado de certas atitudes frente aos cidadãos, agora tais previsões ganham uma nova força positiva, no sentido de obrigar o Estado a tomar certas atitudes, inclusive a intervenção na atividade privada para proteger determinado grupo difuso de indivíduos, como os consumidores. Daí a tendência do legislador moderno, que procura garantir a eficácia prática dos novos direitos fundamentais do indivíduo, dentre eles os direitos econômicos, através da inclusão destes objetivos constitucionais em normas ordinárias de direito privado, como é o caso do próprio Código de Defesa do Consumidor. (2006. p. 164-165).
\end{abstract}

Portanto, a partir da premissa que o Estado fornece mecanismos para criação de atores que possuem a funcão de mediar as relações de consumo, buscando equilibrar as partes, evitar ou, se for o caso, solucionar os conflitos consumeiristas. Ademais, "as estruturas que buscam regular as relações de consumo atuam no sentido de garantir que o consumidor possa exercer os seus direitos" (SILVA, 2015, p. 280).

Em relação aos Procons, órgãos estaduais e municipais de defesa do consumidor, possuem como uma de suas atribuições aplicar as sanções administrativas aos fornecedores que violam normas voltadas à proteção dos direitos e dos interesses dos consumidores.

O Procon, além de possuir a aplicação de sanções administrativas, exerce fundamental importância, devido ao fato que promove um trabalho de informação dos direitos dos consumidor e, também, de conciliação entre as partes. Mas, deve-se atentar ao disposto no artigo 82, III, do CDC, o qual autoriza o Procon a ajuizar ações coletivas para a tutela dos direitos difusos, coletivos e individuais homogêneos do consumidor.

Silva anlisa fatores acerca da importancia com que se deve visualizar os órgãos administrativos de proteção e defesa do consumidor. Isso porque, muitas vezes,

[...] acabam sendo o primeiro e único atendimento ao qual o cidadão recorre na busca de solução para o conflito. $\mathrm{Na}$ grande maioria das demandas, os órgãos administrativos conseguem obter a harmonização entre as partes, por isso, é fundamental que se conheça o papel que cada órgão desempenha no sistema (2015, p. 282). 
Atualmente, no Rio Grande do Sul, o aparato institucional é ainda insuficiente para a efetiva defesa do consumidor em todas as regiões do estado (PILAU SOBRINHO; ETGES, 2012, p. 9). Atualmente pode-se citar como grande associação de defesa do consumidor o IDEC - Instituto Brasileiro de Defesa do Consumidor, o qual foi em 1987, e, é uma associação de consumidores sem fins lucrativos e independente de governos, empresas ou partidos políticos. O IDEC promove a educação, a conscientização, a defesa dos direitos do consumidor e a ética nas relações de consumo. Outra associação civil de âmbito nacional, com caráter científico, técnico e pedagógico, criada para promover a defesa dos interesses dos consumidores é o BRASILCON - Instituto Brasileiro de Política e Direito do Consumidor.

Concorda-se com Schmidt, quando o autor enfatiza que é impossível tratar o assunto políticas públicas de forma isolada, pois é preciso inserir o Estado e a sociedade no contexto. Isso porque verifica-se que as "políticas públicas não são uma espécie de setor de departamento com vida própria. Elas são o resultado da política, compreensíveis à luz das instituições e dos processos políticos” (2008, p. 2.310), estes por sua vez vinculados às questões gerais da sociedade.

\section{Conclusão}

A presente pesquisa teve como objetivo principal analisar a concretização dos direitos do consumidor sob o prisma da (in)eficiência da proteção dos mesmos, os quais se veem vulneráveis quando não podem contar com órgãos de defesa em seus municípios. A princípio cabe dizer que ocorreu um imensurável avanço com o advento do Código de Defesa do Consumidor, no que a defesa dos consumidores passou a ser vislumbrada e traduzida como um direito fundamental.

Visualiza-se, assim, a essencialidade em torno da implementação de políticas públicas no cenário consumerista, especialmente porque, conforme enfatiza Silva, além do necessário reconhecimento, "é preciso que haja a definição de instrumentos que possam concretizá-los. Sem a presença do Estado no papel de agente regulador das relações, apenas amplia-se a vulnerabilidade do consumidor-cidadão" (2015, p. 278).

Porém, ainda ocorre resistência e afrontas à lei consumerista, devido à falta de informação dos consumidores sobre seus direitos, fator que representa um problema mais 
ideológico e político, de que deveria ser imparcial no que tange a proteção dos consumidores, devendo efetivar órgãos estaduais e municipais de defesa do consumidor.

Atualmente, no Rio Grande do Sul, de um total de 497 municípios, existem 85 órgãos municipais de defesa do consumidor e 28 Balcões do Consumidor, o que demonstra a total fragilidade do sistema em amparar o elo mais fraco da relação.

Pois, a realidade inerente ao dever, positivada nos textos legais, e o campo do ser, realidade enfrentada pelos consumidores diariamente ainda é considerada ineficiente, pois o atendimento não condiz com a dignidade da pessoa humana.

Essa problemática nos leva a considerar a importância de o consumidor visualizar a garantia e a seguridade de seus direitos. Por mais que muitas vezes não compreenda seu papel no seio de uma relação entre fornecedor e consumidor, cabe ao Estado, por meio dos mecanismos a seu dispor, promover um olhar efetivo para com o tratamento dos direitos dos consumidores. 


\section{Referências}

BONATTO, Cláudio. Questões controvertidas no Código de Defesa do Consumidor: principiologia, conceitos, contratos atuais. 5 ed. Porto Alegre: Livraria do Advogado, 2009.

BRASIL. Código de Defesa do Consumidor. Disponível em: <http://www.planalto.gov.br/ccivil_03/leis/l8078.htm>. Acesso em: 6 set., 2019. CAVALIERI FILHO, Sergio. Programa de direito do consumidor. 2. ed. São Paulo: Atlas, 2010.

HABERMAS, Jürgen. Direito e democracia: entre facticidade e validade. v. I. Tradução Flávio Beno Siebeneichler. Rio de Janeiro: Tempo Brasileiro, 2003.

HABERMAS, Jürgen. Historia y crítica de la opinión pública: la transformación estructural de la vida pública. Naucalpan: G. Gili, 2002.

LEAL, Rogério Gesta. Estado, administração e sociedade: novos paradigmas. Porto Alegre: Livraria do Advogado, 2006.

MARQUES, Cláudia Lima. Contratos no Código de Defesa do Consumidor: o novo regime das relações contratuais. 7. ed. São Paulo: Editora Revista dos Tribunais, 2014.

MARQUES, Cláudia Lima. Contratos no Código de Defesa do Consumidor: o novo regime das relações contratuais. 6. ed. São Paulo: Revista dos Tribunais. 2011.

MORAES, Paulo Valério Dal Pai. Código de Defesa do Consumidor: o princípio da vulnerabilidade no contrato, na publicidade, nas demais práticas comerciais: interpretação sistemática do direito. 3. ed. Porto Alegre Livraria do Advogado, 2009.

MOREIRA, Luiz. A fundamentação do direito em Habermas. Belo Horizonte: Mandamentos/Fortlivros, 1999.

NETO, Zaiden G.; COSTA, Kerto Nascimento. Eficácia do Código de Defesa do Consumidor em Face do Tratamento Diferenciado aos Consumidores na Fase Pós-Venda, por Parte dos 
Serviços de Atendimento ao Consumidor. Sequência, Florianópolis, n. 71, p. 221-238, dez. 2015.

OKAZAKI, Ana C. Noronha Gonçalves; AZEVEDO, Anderson. Por uma interpretação tópica das normas de proteção ao consumidor. In: MEZZAROBA, Orides; FEITOSA, Raymundo U. Rego; SILVEIRA, Vladimir Oliveira; SÉLLOS-KNOERR, Viviane Coêlho. (Org.). Direito do Consumidor. Curitiba - PR: Clássica Editora, 2014. p. 445.

PILAU SOBRINHO, Liton Lanes; ETGES, Filipe Madsen. (Orgs.). A municipalização do Sistema de Defesa do Consumidor : cartilha para criação do PROCON municipal / Assembleia Legislativa do Estado do Rio Grande do Sul. Comissão de Assuntos Municipais. Porto Alegre: CORAG, 2012. 34 p.

SCHMIDT, João Pedro. Para entender as políticas públicas: aspectos conceituais e metodológicos. In: REIS, Jorge Renato dos; LEAL, Rogério Gesta (Org.). Santa Cruz do Sul: Edunisc, 2008.

SCHMITT, Cristiano Heineck. Consumidores Hipervulneráveis: a proteção do idoso no mercado de consumo. São Paulo: Atlas, 2014.

SILVA, Edgar Moreira. Introdução: $\mathbf{O}$ direito do consumidor no $3^{\circ}$ milênio. Caderno Jurídico Escola Superior do Ministério Público de São Paulo, São Paulo, Ano 3, v. 2, n. 6 , jan., 2004.

SILVA, Rogério da. A defesa do consumidor: políticas públicas e fortalecimento das estruturas que regulam as relações de consumo. In: SÁNCHEZ BRAVO, Alvaro; GOREZEVSKI, Clóvis; PILAU SOBRINHO, Liton Lanes (Org.). Direitos humanos \& filosofia do direito. Passo Fundo: Editora Universidade de Passo Fundo, 2015. 